\title{
DESIGN AND CONSTRUCTION OF ARDUINO BASED OBSTACLE ROBOT
}

\author{
Smt. Sushmita Deb \\ Assistant Professor \\ E\&E Department, SJMIT \\ Chitradurga, Karnataka, India \\ Ruksar Fathima, Bosaiah M, Anjana S N, Manasa L \\ Student $8^{\text {th }}$ Sem. \\ E\&E Department, SJMIT
}

\begin{abstract}
This paper presents a project of designing an obstacle avoidance robot which works using a ultrasonic sensor. Basically obstacle avoidance means it is the technique which satisfy a property of controlling a body without intersection with the other body. Whenever some object appears in front of the robotic vehicle it tends to move away from it so as to avoid the manual operation of the robot to move a robot.

The project has a robotic vehicle which includes Arduino board through which programming is done so as to move the robot and an ultrasonic sensor through which the body appearing in front of robot can be detected and it sends a signal to prevent it from colliding and move in a different direction. This robotic vehicle is built, using a motor driver circuits. Depending on the input signal received from the ultrasonic sensor, the micro-controller in the Arduino sends the signal to the motor driver to move the robotic vehicle in other direction to prevent it from collision with other bodies.
\end{abstract}

Hence, this paper presents the operation of an obstacle avoidance robot using an ultrasonic sensor, motor driver, Arduino, and a source to run the robot.

\section{INTRODUCTION}

Automation or Robotics is the new set of technology that has been evolved in this era, this technology has replaced machines or robots with the man with more accuracy and more efficient work. The Robotics has been emerged in day to day life. The Robotics is growing so widely with the knowledge of Physics, sensors, materials, control, dynamics structures and programming. With this evolving change Robotics has made its place in each and every sector including industrial agricultural and in many hardware and software Sectors.

Robotics play a very vital role in autonomous area. Here we are going to design a robot which is known as obstacle avoidance robot. Obstacle avoidance robot is the one which avoid the intersection or collision with the front bodies which appear knowingly or unknowingly. Ultrasonic sensor placed in the robot can detect an object appearing in front of the robot and the sensor provides the signal to move robot in the particular direction and with the help of the Arduino UNO, the microcontroller within it will direct the motor to change its direction to the other avoiding collision with the appearing objects.

In this project an Arduino board is used to program such application of obstacle avoidance and motor driver circuit to control the Wheels of the robot to move in a desired direction, and ultrasonic sensor to sense the appearing object in front of the robot and to measure the distance between the object and the robot.

Obstacle avoidance robot specifies it in many ways by using different types of sensors. This robot finds its application in many industrial areas like automatic cars, robots in spacecraft's etc.

\section{METHODOLOGY}

The block diagram of the proposed system is as shown in the following diagram

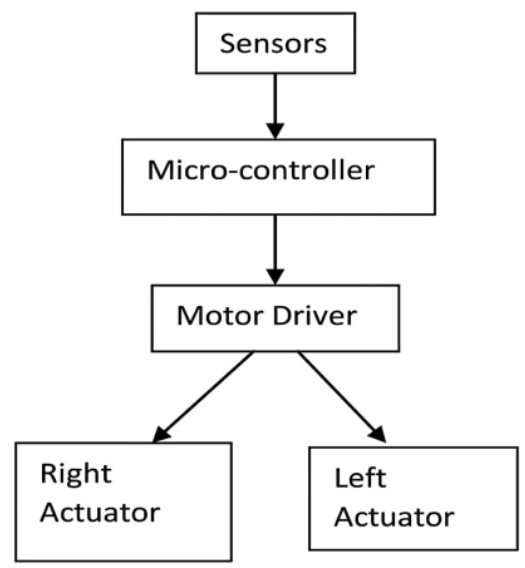

Fig 1. Block diagram of the system. 


\section{International Journal of Engineering Applied Sciences and Technology, 2020 Vol. 4, Issue 12, ISSN No. 2455-2143, Pages 426-429 \\ Published Online April 2020 in IJEAST (http://www.ijeast.com)}

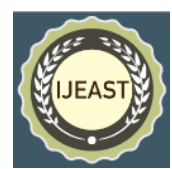

The block diagram gives the total idea of the obstacle avoidance robot.

The obstacle avoidance means it is a property which avoids the upcoming object to collide or intersect with obstacle or the other objects. The Robot is designed in a basic way of using a robot chassis and fixing the particular sensors and other materials in a particular manner.

Firstly to Arduino board, a program is designed to process the signal given by the sensor and produce the output as per the operation. The operation includes, when the robot is powered on, that is both the actuators or Motors are moving in clockwise direction then the robot tend to be moving in forward direction, and if any object appears in front of the robot, then the ultrasonic sensor placed in the robot will automatically sends the signal to the microcontroller of Arduino Uno and this direct the motor driver to move the left actuator in clockwise and right actuator in anticlockwise direction. So that the robot can change its direction and avoid the robot by colliding with the obstacle appearing in front of the robot.

In a similar way whenever an object tends to appear in front of the robot the robot will automatically changes its direction. With the distance of $17 \mathrm{~cm}$ from robot to the object the ultrasonic sensor sends the signal and the operation is carried on. If the right distance is more than the left distance, the robot move to the right direction and this process continuous and robot keeps to move without colliding with the obstacle.

Materials used to design an obstacle avoidance robot

- Arduino Uno

- Ultrasonic sensor

- Geared motor

- Servomotor

- Robot Chassis

- Motor Driver

- Battery Connector

- Connecting wires

- Jumper wires

- Battery

A. Arduino Uno:

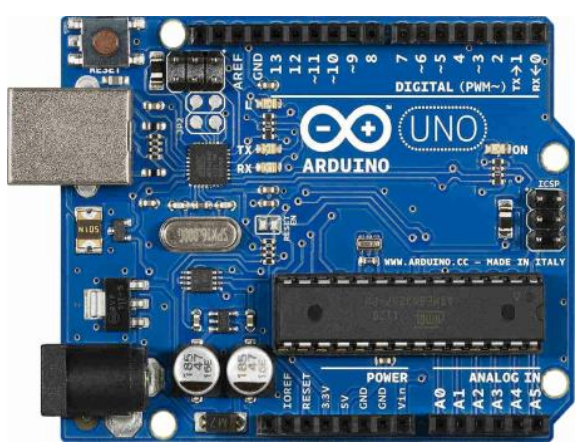

Fig 2. Arduino Uno board

The Arduino UNO is a micro-controller board which has an microchip atmega328 $\mathrm{P}$ as microcontroller. This chip is proposed by arduino.cc. this board has both analog and digital input/output pins, so that it can be interfaced with other board or others circuit to use it for many more operation.
The Arduino board has 14 pins in total of which 6 pins can provide PWM output and has a flash memory of $32 \mathrm{~KB}$ of which $0.5 \mathrm{~KB}$ is used by bootloader. The board basically works with the input voltage of 7-20 volts and with operating voltage of $5 \mathrm{~V}$ volts and it is having a clock of $16 \mathrm{Mhz}$. Through this board serial communication is also possible and this board is used for many more electronics operation.

\section{B. Ultrasonic sensor (HC-SR04):}

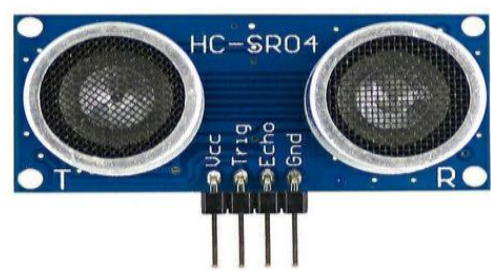

Fig 3. Ultrasonic Sensor HC-SR04

The ultrasonic sensor is the one which detect object presented in front and find the distance between the sensor and the object placed before it. The ultrasonic sensor has two transducers namely, a microphone and speaker. Without contacting with the body this sensor detects a body with high accuracy. This sensor works with the input voltage of 5 Volts. The advantage of using the sensor is that it gets unaffected by sunlight or black materials.

\section{Motor driver (L298N):}

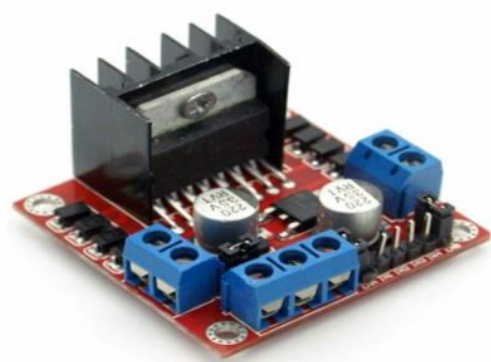

Fig 4. Motor driver

Many kinds of motor driver circuits has been used depending on controlling the number of Motors. The L298N motor driver has been used. The $\mathrm{L} 298 \mathrm{~N}$ is the dual channel motor and is capable of operating two pair of DC Motors at a time. That is, this circuit can be able to run the two Motors at the same time with the same source. The power supplied to this circuit is 12 Volts and 2 Ampere and it can give output of 5-7 Volts.

\section{PROGRAM TO RUN THE OBSTACLE ROBOT:}

Int echoPin = 8;

Int trigPin = 7;

Int fwdleft $=7$;

Int revright $=2$;

Int revleft $=4$; 
Int fwdright $=3$;

Int $\mathrm{c}=0$;

Void setup()

\{

//Serial.begin(4800); pinMode(3, OUTPUT); pinMode(4, OUTPUT); pinMode(2, OUTPUT); pinMode(5, OUTPUT); pinMode(trigPin, OUTPUT); pinMode(echoPin, INPUT); \}

Void loop() \{

Long duration, distance; digitalWrite(trigPin,HIGH); delayMicroseconds(1000); digitalWrite(trigPin, LOW); duration=pulseIn(echoPin, HIGH); distance $=($ duration $/ 2) / 29.1$;

//Serial.print(distance);

//Serial.println(“CM”);

Delay(10);

If((distance>17))

digitalWrite(3,HIGH); digitalWrite(2,LOW); digitalWrite(4,LOW); digitalWrite(5,HIGH);

Else if(distance<17)

digitalWrite(3,HIGH); digitalWrite(2,LOW); digitalWrite $(4, \mathrm{HIGH})$; digitalWrite(5,LOW); \}

\}

\section{ALGORITHM}

The Algorithm of the proposed system is as shown in the following figure. The ultrasonic sensor placed in the robot has two transducers which emits high and short frequency signals. If any object appears in front of the sensor, then the echo pin will takes a signal as a Input and produces that signal to the microcontroller. Firstly, we initialize the robot where it will be running in forward direction that both the Wheels of the motor in clockwise direction. While moving, if any object appears in front of the robot then the robot have two choices that it will move further or it will measure the distance and alert the microcontroller to direct the driver to move the wheels in other direction then, the robot check for the moderate distance that whether to move in left or right direction, while deciding for the moderate distance the speed will gets reduced and if the distance to the left is more than the robot moves in left direction and it has a shortest distance then the robot will stop. When the robot will get a largest distance away from the obstacle it will move in that particular direction and then run the robot in forward direction and this continuous without hitting the obstacle appearing in front of the robot.

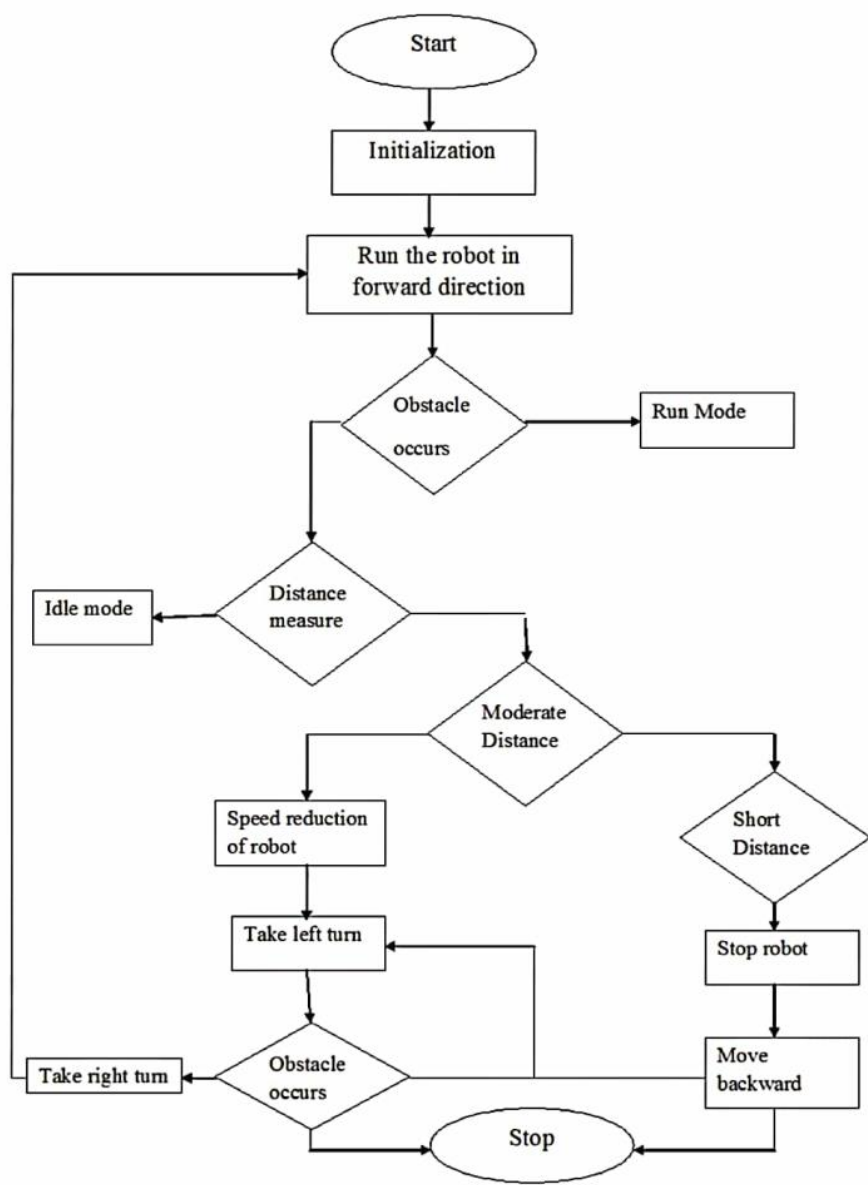

Fig 5. Obstacle Avoidance Flowchart

\section{ADVANTAGES:}

- This application is easy to install and easy to operate.

- More reliable than manual Operation.

- Sensors based input measuring and control. Microcontroller based reliable design.

- Easy to operate and less manpower based design.

- Efficient design and Easy to operate.

- Eliminates Manual operations.

- Fast response Useful for multi industrial automation.

\section{DISADVANTAGES:}

- Periodic monitoring is needed.

- Careful handling of Sensors is required.

\section{APPLICATIONS:}

- $\quad$ All kind of industries and automatic industries.

- Steel industries/factories.

- Food making automobile industries.

- Automobiles like (cars, vans and heavy industry) 


\section{International Journal of Engineering Applied Sciences and Technology, 2020 \\ Vol. 4, Issue 12, ISSN No. 2455-2143, Pages 426-429 \\ Published Online April 2020 in IJEAST (http://www.ijeast.com)}

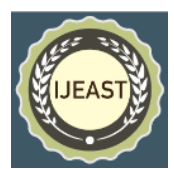

- Small scale spare part design industries.

- Embedded system

\section{CONCLUSION}

This project develop will detect an obstacle appearing in front of the robot and also prevent it from colliding with that obstacle. This robot is fully automatic and can be used even in the absence of manual operation. For the further this robot can be upgraded by using different kinds of sensor to use it in different fields like fire detecting, weather checking, and also by using GSM we can use it for many application. This robot performs with a good accuracy and efficiency.

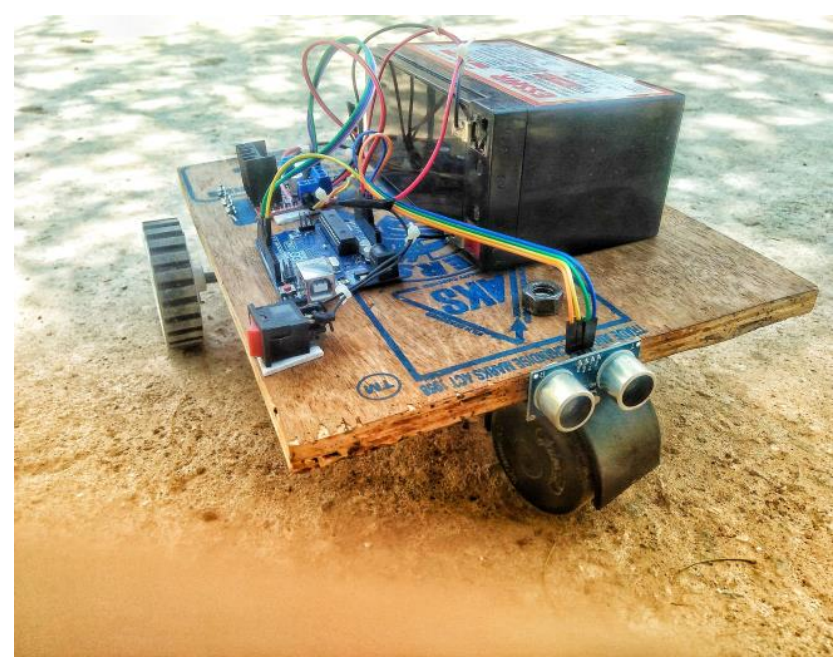

Fig 6. proposed obstacle robot

\section{REFERENCES}

1. Gray, K. W , (2000). "Obstacle Detection and Avoidance for an Autonomous Farm Tractor. Utah State University".

2. J. Hrabek and B. Honzik, (2002) "Mobile robots playing soccer," in Proceedings of 7th International Workshop on Advanced Motion Control, pp. 510-513.

3. Z. M. Liu Xuan and L. Wei, (2008) "Methods of modular robot design", in Pro-ceedings of Second International Symposium on Intelligent Information and Technology Application, pp. 663-668.

4. R. Siegwart and I. R. Nourbakhsh, (2004) Introduction to Autonomous Mobile Robots, ser. Intelligent Robotics and Autonomous Agents. MIT Press.

5. K. V. A. Tsalatsanis and N. Tsourveloudis, (2007) "Mobile robot navigation using sonar and range measurements from uncalibrated cameras," Journal of Intelligent and Robotic Systems, vol. 48, pp. 253-284.
6. W. H. Dimitrios Loannou and A. Laine , (1990) "Comparative study of hough transform methods for circle finding", Journal of Image and Vision Computing, vol. 8, pp. 71-77.

7. N. Kehtarnavaz and M. Gamadia, (2006) Real-Time Image and Video Processing, (From Research to Reality). Morgan and Claypool Publishers.

8. R. C. Gonzalez and R. E. Woods,(2003) Digital image Processing. Pearson Education.

9. V. Hanumante et al., (2013) "Low Cost Obstacle Avoidance Robot" in International Journal of Soft Computing and Engineering, Vol. 3, Issue-4.

10. ATMEGA328P Datasheet, ATMEL Corporation, San Jose, CA, 2008

11. M. Nasucha, (2015) "Design and Development of an Interface Module for Obstacle Avoiding Robots", Microcontroller Lab, Univ. Pembangun Jaya, Tangerang Selatan, Indonesia.

12. M. Jouaneh, (2012) "Proximity Measurement" in Fundamentals of Mechatronics, SI Edition, United States: Nelson Engineering, ch.7, sec. 7.4, pp. 221229.

13. M. Nasucha, (2015) "Design and Development of a Visible Light Sensor Module for Obstacle Avoiding Robots", Microcontroller Lab, Univ. Pembangunan Jaya, Tangerang Selatan, Indonesia. 